\title{
Educar para alteridade na formação de professores de química: experiências vividas com a educação de surdos
}

\author{
Educar para la alteridad em la formación de profesores química: \\ experiências vividas com la educación de sordos
Educating for otherness in the training of chemistry teachers: experiences with the education of the deaf

\author{
Ana Luiza Alves Constantino ${ }^{1}$ \\ Aline Machado Dorneles ${ }^{2}$
}

\begin{abstract}
Resumo
O presente artigo apresenta as experiências vividas na formação de professores de Química em uma escola bilíngue para estudantes surdos. A pesquisa foi realizada no âmbito da disciplina de Educação Química V no curso de Química Licenciatura da Universidade Federal do Rio Grande - FURG. Busca-se compreender a experiência de formação docente na presente disciplina a partir dos pressupostos teóricos e metodológicos da pesquisa narrativa. Para isso, analisam-se as escritas narrativas dos professores formadores e dos licenciandos a respeito da experiência de visitar o contexto de uma escola bilíngue e a experiência de receber os estudantes surdos na universidade, especificamente, no laboratório de química. As narrativas apontam relevantes aprendizagens relacionadas ao reconhecimento do outro, ao educar para alteridade no ensino de Química e os desafios de promover a inclusão na Química. Retratam também a experiência de professores em formação em parceria com seus licenciandos ao vivenciar o contexto de uma escola bilíngue para educação de crianças, jovens e adultos surdos. São narrativas que fortalecem a intenção de problematizar a inclusão e o exercício de alteridade na sala de aula e na formação inicial de professores de Química. Entende-se que o exercício da alteridade inicia quando percebemos que a primeira língua do surdo não é o português, e assim o desafio de pensar uma prática pedagógica acolhedora e que produza significados na construção do conhecimento científico.
\end{abstract}

Palavras-Chave: Educação Química; Escrita Narrativa; Experiência Docente; Formação de Professores; Surdez

\section{Resumen}

O presente artículo como experiencia vivida en la forma de profesores de química en la escuela primaria para estudiantes estudiados. Realización de estudios de disciplina de la educación química y curso de Química Licenciatura de la Universidad Federal del Río Grande - FURG. Busque y compreender una experiencia de formación docente en el presente tema a partir de pressupostos teóricos e metodological da pesquisa narrativa. Para ello, analice las escrituras narrativas de la profesión y la licenciatura y la experiencia en el contexto del contexto escolar de la escuela y la experiencia del estudiante en estudios universitarios, específicamente, no laboratório de la química. Como parte de las narrativas, se mencionan conocimientos relacionados con el reconocimiento, la educación y la alteración de la química y los desafíos para promover la inclusión de la química. Retratam também una experiencia de profesorado en formación en parceria com seus licenciandos ao vivenciar el contexto de la escuela primaria para la educación de crianças, jovens e adultos surdos. Esas narrativas que fortalecen una intenção de problematizar e incluir el ejercicio de alteración en la sala de aula y la forma inicial de los profesores de química. Entender que el ejercicio de la alteración inicia la redacción de la información sobre la redacción y el desarrollo, así como el desafío de pensar en la práctica pedagógica y la producción y el significado científico.

\footnotetext{
${ }^{1}$ Mestranda em Química Tecnológica e Ambiental - FURG, Rio Grande, Rio Grande do Sul; Brasil; analuizaconstantino@gmail.com

${ }^{2}$ Doutora em Educação em Ciências, Química da Vida e da Saúde - FURG; Rio Grande, Rio Grande do Sul; Brasil; lidorneles26@gmail.com
} 
Palabras claves: Educación Química; Escritura Narrativa; Experiencia Docente; Formación de profesores; Sordera

\begin{abstract}
This article presents the experiences of the training of chemistry teachers in a bilingual school for deaf students. The research was carried out under the discipline of Chemical Education V in the Chemistry Degree course of the Federal University of Rio Grande - FURG. The aim is to understand the experience of teacher education in this discipline based on the theoretical and methodological presuppositions of narrative research. In order to do this, the narrative writings of the trainer and the licentiate students are analyzed regarding the experience of visiting the context of a bilingual school and the experience of receiving deaf students at the university, specifically in the chemistry laboratory. The narratives point to relevant learning related to the recognition of the other, by educating for otherness in the teaching of Chemistry and the challenges of promoting inclusion in Chemistry. They also portray the experience of a teacher in training in partnership with her graduates in experiencing the context of a bilingual school for the education of children, young people and deaf adults. These are narratives that strengthen the intention to problematize the inclusion and exercise of alterity in the classroom and in the initial training of Chemistry teachers. It is understood that the exercise of alterity begins when we perceive that the first language of the deaf is not Portuguese, and thus the challenge of thinking a pedagogic practice welcoming and that produces meanings in the construction of scientific knowledge.
\end{abstract}

Keywords:Chemical Education; Narrative Writing; Teaching Experience; Teacher Training; Deafness

\title{
1. Introdução
}

A inclusão é um tema que geralmente é pouco abordado nos currículos dos cursos de licenciaturas diante da sua complexidade e grandes desafios que são apresentados nesse âmbito. A Química é uma ciência exata presente no ensino médio e no currículo de Ciências do ensino fundamental, sendo frequente a dificuldade de compreensão e entendimento por muitos alunos em todos os níveis de ensino. Diante disto, o ensino de Química para estudantes surdos torna-se um desafio, porém entendemos a importância da inclusão ser abordada no currículo dos cursos de Química Licenciatura, visto que, a realização de um bom planejamento, com novas metodologias de ensino e o exercício da alteridade são capacidades essenciais e necessárias para um professor em formação.

Nesse contexto, apresentamos a experiência vivida por licenciandos de Química e seus professores formadores com estudantes surdos do $9^{\circ}$ ano do ensino fundamental vindos de uma escola bilíngue na cidade de Rio Grande - RS, através da disciplina de Educação Química V do curso de Química Licenciatura da Universidade Federal do Rio Grande FURG, também localizada na cidade do Rio Grande, Rio Grande do Sul. A experiência é documentada por meio das escritas narrativas realizadas pelos licenciandos, com a intenção de compreender como foi dada a experiência em visitar uma escola bilíngue e receber os estudantes surdos no ambiente da universidade, mais especificamente, nos laboratórios de Química do departamento da Escola de Química e Alimentos da FURG.

$\mathrm{Na}$ formação de professores a escrita narrativa tem sido uma ferramenta comumente utilizada para compreender melhor o processo de formação de docente. É oportunizado pela 
escrita narrar à experiência docente e os fatos que se tornaram mais significativos no contexto da sala de aula, desse modo, é possível caracterizar essas escritas como elementos produtores de conhecimentos. Também como, este tipo de escrita apresenta um enfoque de pesquisa particular, na qual em maioria das vezes há o envolvimento do professor sendo o autor do enredo a ser pesquisado (BRUNER, 2001; DORNELES e GALIAZZI, 2012; SUÁREZ, 2008). Dessa forma, concorda-se com Dorneles e Galiazzi (2012) da importância da escrita narrativa na formação de professores Química:

A experiência, quando escrita, favorece a reflexão a respeito do fato narrado, $\log o, o$ desafio que se estabelece é o de escrever sobre a experiência da docência. Nesse sentido, compreende-se que as histórias, ao serem narradas, tornam-se dispositivos para se pensar acerca da formação do professor e, nessa direção, possibilita ao autor da história e ao outro que a lê pensar sobre sua ação docente e sua formação, viabilizando que outras histórias possam ser narradas (DORNELES e GALIAZZI, 2012 p. 258).

Desse modo, as histórias vindas da experiência com alunos surdos possibilita ao professor em formação inicial discutir, vivenciar e pensar no sujeito que possui a surdez, tendo a clareza que esse sujeito interage com o mundo, e é neste meio de interação que ocorre a apropriação de forma peculiar da experiência visual percebendo a tradição e as estimas nesse contexto (GONZAGA; CORREAA e DE PAULA, 2013). Concordamos que: "Vivenciar novas experiências nos permite ampliar os horizontes quanto à diversidade que está a nossa volta. Tentar refletir sobre a perspectiva do outro com alteridade também nos possibilita aprendizagens para o ato de ensinar." (SILVA, 2016, p. 77). Diante isso, acreditamos que o educar para alteridade faz-se importante na formação de professores e torna-se essencial de ser trabalhado em seu currículo de formação.

\section{Metodologia}

A pesquisa emergiu das atividades realizadas na disciplina de Educação Química V do $5^{\circ}$ semestre do curso de Química Licenciatura da FURG, que possui o tema inclusão. A disciplina não possui pré-requisito e por isso participaram da atividade licenciandos provenientes de diversos semestres. Decidimos focar no estudo sobre o ensino de Química para estudantes surdos, com o objetivo de desenvolver uma educação para alteridade na formação inicial de professores de Química.

$\mathrm{Na}$ ementa da disciplina de Educação Química $\mathrm{V}$ a temática inclusão promove a discussão das práticas pedagógicas na formação de professores de Química. Assim, no segundo semestre de 2017, período em que foi realizado esta atividade, as discussões foram relacionadas ao ensino de Química para estudantes surdos. Visto que na cidade do Rio 
Grande, recentemente, teve a inauguração da primeira Escola Municipal Bilíngue Carmem Baldino para estudantes surdos. A escola atende estudantes da Educação Infantil aos Anos Finais do Ensino Fundamental em turno integral, e também da Educação de Jovens e Adultos. É válido salientar que esta escola é a sétima escola bilíngue criada no país.

Nos encontros semanais da disciplina tivemos um primeiro momento de estudo teórico a respeito da inclusão no ensino de Química. Cada grupo escolheu um artigo com alguma experiência de inclusão, e socializou o estudo na disciplina. De acordo com Leite e Leite (2012):

A inserção da linguagem de sinais no contexto do Ensino de Química, tem sido trabalhada há pouco tempo. Viu-se a necessidade das pessoas surdas entrarem neste novo mundo de descobertas. A dificuldade do ensino-aprendizagem com surdos é estritamente igual ao de pessoas ouvintes. São pessoas dotadas também do intelecto, então tem capacidades normais de aprendizagem (LEITE e LEITE, 2012, p. 2).

Diante disso, acreditamos que é necessário educar para alteridade e para isso a formação inicial de professores é o caminho. Dessa forma, concordamos com o seguinte trecho sobre papel do ensino de ciências: "Nessa vertente, o ensino de ciências possui importante papel. Voltado para uma educação emancipatória, colaborativa na promoção intelectual dos indivíduos e em sua participação na tomada de decisões relativas à aplicação dos novos conhecimentos na sociedade.” (SILVEIRA e SOUSA, 2011, p.36).

A inclusão escolar é uma temática que possui grande relevância e cada vez mais está ganhando espaço em debates e discussões que mostram a necessidade da escola a atender às diferenças intrínsecas à condição humana. No Brasil, documentos como a Constituição Federal de 1988, art. 208, inciso III (BRASIL, 1988), o Plano Decenal de Educação para todos, 1993 - 2003 (MEC, 1993) e os Parâmetros Curriculares Nacionais (MEC, 1999) defendem e asseguram o direito de todos à educação. De acordo com esses documentos, independente das condições físicas, intelectuais, sociais e emocionais, todas as crianças devem ser acolhidas pela escola (SILVEIRA e NEVES, 2006). Diante disso, a reforma inclusiva trata-se de uma reforma educacional mais profunda, que além de permitir o acesso de alunos com deficiência à escola regular, abrange os valores e as práticas para um novo sistema educativo voltado a inclusão (RODRIGUES e LIMA-RODRIGUES, 2011). E por isto, ressaltamos a importância do estudo da inclusão na formação de professores de Química, o desenvolvimento de atividades como esta descrita nesse âmbito propiciam um melhor acolhimento e aprendizagem dos estudantes, como também, preparam melhor o licenciando e o deixam mais confiante para uma futura sala de aula inclusiva. 
Num segundo momento, tivemos a oportunidade de conhecer a proposta de ensino da Escola Bilíngue para estudantes surdos. Realizamos uma Roda de Conversa com a professora da sala de recursos, e posteriormente, fomos acolhidos pela professora de Ciências/Química na Escola, com a proposta de visita e reconhecimento da proposta de ensino. O terceiro momento da disciplina foi à visita dos estudantes surdos aos laboratórios de Química da FURG.

A visita aos laboratórios de química foi realizada pela turma de $9^{\circ}$ ano, com a presença de três estudantes surdos, a professora de ciências da escola bilíngue, uma interprete, dez licenciandos e dois professores supervisores da disciplina de Educação Química V. Organizou-se essa atividade em dois momentos: o primeiro momento os alunos puderam visitar os laboratórios de química e conhecer mais sobre o seu funcionamento, no segundo foram realizados dois experimentos no laboratório de Química Geral: leite psicodélico e a pasta de dente de elefante. O experimento do leite psicodélico consiste na mistura de corantes e detergentes em leite formando uma mistura colorida, como objetivo, este experimento consiste em explicar a interação entre os compostos presentes no leite e no detergente. Por se tratar de um experimento simples com reagentes de fácil manuseio, os estudantes o realizaram sozinhos. O esquema do procedimento é mostrado na figura 1.

\section{- Experimento Leite Psicodélico}

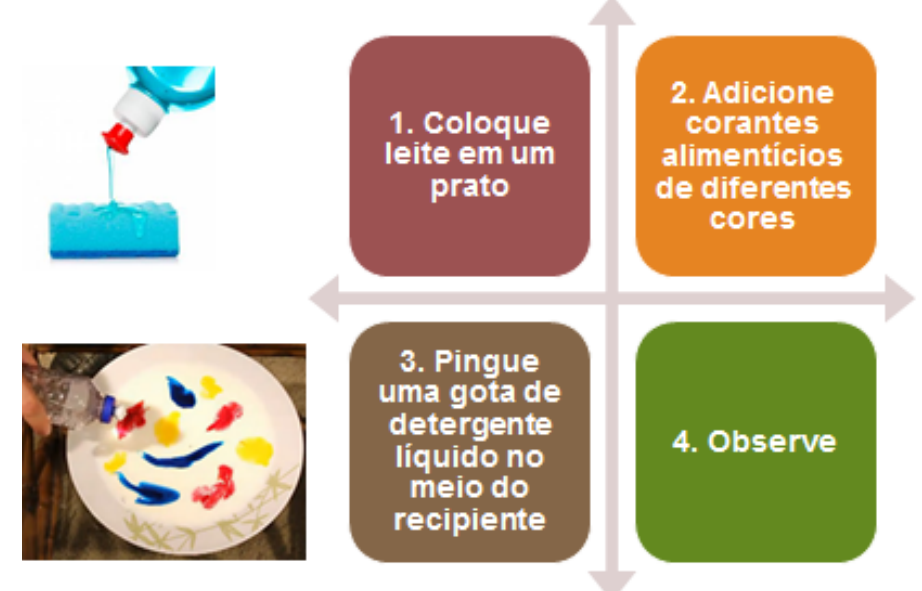

Figura 1 - Esquema do experimento do leite psicodélico

Fonte: adaptado de FOGAÇA, J. Canal do Educador

A pasta de dente de elefante trata-se de um experimento que possui reagentes mais perigosos como o peroxido de hidrogênio e por isto foi realizado de forma demonstrativa. Esse experimento ajuda os alunos no aprendizado de conteúdos como reações químicas. $\mathrm{Na}$ figura 2 é demonstrado o esquema do experimento da pasta de dente de elefante. 


\section{- Experimento Pasta de Dente Elefante (demonstrativo)}

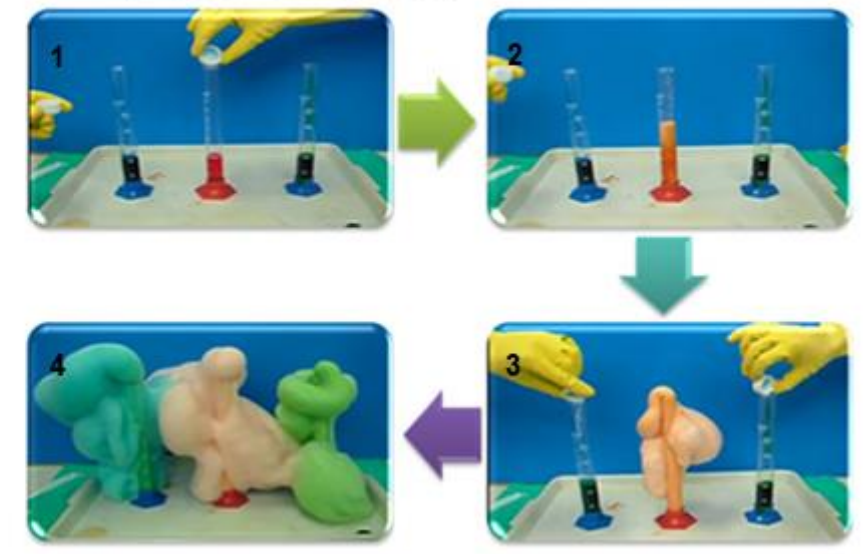

Figura 2 - Esquema do experimento da pasta de dente de elefante Fonte: adaptado de FOGAÇA, J. Canal do Educador

Conforme Skliar e Quadros (2000) a experiências para os surdos ocorrem de maneira visual:

A experiência é visual desde o ponto de vista físico (os encontros, as festas, as estórias, as casas, os equipamentos...) até o ponto de vista mental (a língua, os sonhos, os pensamentos, as idéias...). Como conseqüência é possível dizer que a cultura é visual. As produções lingüísticas, artísticas, científicas e as relações sociais são visuais (SKLIAR e QUADROS, 2000, p. 21).

Dessa forma, foram escolhidos experimentos que trabalham mais a característica do visual para facilitar o aprendizado dos estudantes aos conceitos de químicos. Acreditamos que as atividades como essa são importantes para serem trabalhados com professores em formação o preparando para o planejamento de uma aula para uma sala inclusiva.

Ao final da atividade foram construídas pelos professores e licenciandos narrativas da experiência vivida. A narrativa pode ser compreendida como modo de construir conhecimento através das experiências que nos acontecem. Por meio de Dorneles e Galiazzi (2012) explicitamos a forma de como vemos a escrita narrativa como um item essencial a ser trabalhado com professores em formação:

No ato de investigar o espaço escolar e a atuação docente por meio da pesquisa narrativa, os professores, no referido processo de formação, podem narrar experiências, fatos, ações que significam sua sala de aula como problematizadora e formativa. Em outros momentos, podem narrar situações problemáticas, para as quais não encontram respostas; fazem perguntas; e partilham com o outro, no sentido de ouvir o que ele vivência na sua sala de aula. A escrita narrativa promove a mediação; o acolhimento; o espaço para expressar as experiências; os sentimentos e os dilemas da vida profissional e do ser professor (DORNELES e GALIAZZI, 2012, p. 258). 
A formação de professores de Química pode ser refletida como uma experiência a partir dos acontecimentos vividos e dos significados que eles transmitem para quem os viveu, no entanto, é necessário refletir como se é afetado pelo vivido (DORNELES, 2016). Diante disso, narramos nossas primeiras aproximações e aprendizagens a respeito da inclusão da comunidade surda no contexto escolar, bem como os desafios de pensar o ensino de Química, suas terminologias em Libras na produção de materiais pedagógicos.

\title{
3. Resultados e Discussões
}

\subsection{Conversa inicial a respeito da inclusão de estudantes surdos}

A inclusão deve acontecer com seus pares, afirma a professora da sala de recursos, durante a roda de conversa realizada na disciplina de Educação Química V. Ao narrar sua história de formação percebemos o envolvimento, anos de estudo e dedicação pela temática inclusão. A professora narra às experiências vividas no primeiro ano da escola, e reconhece a importância da escola para uma efetiva inclusão da comunidade surda.

\begin{abstract}
"Na escola o currículo é organizado pelas disciplinas e suas áreas de conhecimento, conforme as demais escolas, o diferencial esta no modo como compreendemos o ensino e conteúdo a ensinar. O conteúdo é flexível, pois o estudante surdo precisa visualizar, é necessário o concreto para compreender, isso leva tempo. Na escola os professores necessitam conhecer a história de vida de cada estudante, não há como não se envolver e ser afetado, ao perceber a felicidade de cada estudante em estar na escola. Não gostam de faltar aulas, nas férias ficam incomodados e sentem falta da escola, pois ali se sentem acolhidos e, principalmente, conseguem se comunicar entre seus pares." (Narrativa da professora da Escola Bilíngue).
\end{abstract}

Ressaltamos a importância da conversa com a professora para o desenvolvimento da nossa atividade, através de sua narrativa conseguimos compreender de melhor forma como funciona o dia a dia dos estudantes na escola bilíngue, desse modo, tornou-se mais fácil realizar uma prática que os ajudasse em um aprendizado de Química e Ciências.

\footnotetext{
"Tivemos um estudante de 6 anos que chegou na escola, pois seus pais não sabiam Libras, e logo não conseguiam se comunicar com seu filho. $\mathrm{O}$ menino até ser alfabetizado na sua língua de sinais, tinha um comportamento de revolta, gritava, agredia os colegas e professores. Afinal, como se comunicar? Começamos pela expressão facial, é muito importante, é o começo da comunicação com um estudante surdo. A escola oferece curso de Libras para comunidade, principalmente, os pais e familiares dos estudantes sentem a necessidade de aprender a língua."(Narrativa da professora da Escola Bilíngue).
}

A cultura surda é multiforme, no entanto, apresenta uma característica específica que é a visual e o impacto dessa singularidade é muito significativo. A aprendizagem da criança surda é mais lenta, pois não recebe a mesma quantidade de estímulos que uma criança ouvinte (PEREIRA; BENITE; BENITE, 2011). Assim, os fragmentos narrativos da professora nos ajudaram também a entender que o modo de aprendizado se torna diferente para os estudantes 
surdos, visto que, o visual os chama muita atenção e facilita seu aprendizado. Nesse sentido, esta primeira conversa ajudou a nós, licenciandos e professores formadores a nos ambientar e a pensar em um planejamento que envolve mais atividades visuais, como por exemplo, experimentos que trabalhem mais essa característica.

Era perceptível nosso envolvimento, curiosidade e atenção a narrativa da professora. A professora ao falar nos envolvia com suas expressões faciais de felicidade e envolvimento com a língua brasileira de sinais. Ao mesmo tempo, que contava sua experiência, entrelaçava nesse falar os sinais em Libras, oportunizando uma aprendizagem a cada experiência narrada. Naquela manhã percebemos professores e licenciandos, o quanto seria importante visitar a escola, conhecer os estudantes, ter uma primeira aproximação com o ensino para estudantes surdos, e assim coletivamente aprender e contribuir no ensino da Química nos anos finais do ensino fundamental e do ensino de jovens e adultos. A seguir mostramos uma narrativa de uma licencianda sobre a roda de conversa:

\begin{abstract}
“(...) $\mathrm{Na}$ conversa conseguimos perceber um pouco do cotidiano e a realidade do estudante com a surdez. Os estudantes precisam se adaptar aquele ambiente e as atividades são mais devagar, são feitas com imagem para melhorar o aprendizado e com adaptações para o conhecimento do estudante surdo. Conversamos da dificuldade em encontrar professores que sigam uma carreira voltada para a inclusão, pois além da língua de sinais, esse professor deve ter paciência e amor pelo projeto de inclusão (...)" (Licencianda A/ Estudante de Educação Química V)
\end{abstract}

A estudante ressalta em sua narrativa situações narradas pela professora da escola bilíngue durante a roda de conversa com licenciandos e professores da universidade, como o aprendizado característico de forma mais e visual e atividades realizadas de forma mais devagar. Além disso, a estudante ressalta da dificuldade em encontrar professores que tenham uma carreira voltada para inclusão, pois é necessário muita persistência, carinho, estudo e dedicação para seguir nesse caminho.

Assim, através da narrativa realizada pela licencianda podemos compreender quais os pontos a chamaram atenção nesta conversa inicial com a professora da escola de bilíngue e como se deu a experiência de vivenciar esse momento, as narrativas nos ajudam a refletir sobre a sala de aula e nossa formação docente.

\title{
3.2. Experiências vividas na visita à escola
}

A visita à Escola Municipal Bilíngue Carmem Baldino, foi conduzida pela professora de Ciências/Química da escola. A professora é formada em Química Licenciatura na FURG, fato que chamou atenção dos acadêmicos do curso, ser recebida por uma professora egressa do nosso curso. Realizamos a visita organizada em dois grupos: um grupo no turno da manhã 
e outro grupo no turno da noite. Pela manhã conhecemos os estudantes do turno integral dos anos iniciais e anos finais do ensino fundamental. À noite os estudantes surdos das turmas da EJA.

A escola fica no centro da cidade, facilitando a chegada de estudantes de vários bairros da cidade e de municípios próximos, São José do Norte e Pelotas. Ao chegarmos à escola aguardamos no espaço de convivência, uma sala ampla com sofás e televisão (espaço usado pelos estudantes no intervalo do almoço visto ser uma escola de turno integral). Depois, fomos convidados a conhecer as salas de aula para cada disciplina, são salas temáticas relacionadas ao ensino de português, matemática, geografia e história, ciências, libras, língua estrangeira, artes, dentre outras.

A linguagem é algo bastante significativo na identificação e reconhecimento do ser, pois é através dela que muitas coisas em nossa vida são representadas e reproduzidas. A língua de sinais está associada a uma experiência visual que manifesta as formas da cultura surda. As maneiras de como os surdos percebem o visual é diferente dos ouvintes e possui características que podem ser ininteligíveis a aqueles que não pertencem à cultura surda (QUADROS, 2003). Ao visitar a escola percebemos com nossos próprios olhos os relatos que a professora da escola bilíngue descreveu em visitar a universidade, vimos que, as salas são adaptadas de uma maneira visual com cartazes, imagens, vídeos para ajudar no aprendizado do estudante surdo.

De acordo com Sousa e Silveira (2011), conceito de linguagem científica como mol, elétron, íon entre outros, não compõem o rol de terminologia em libras, o que se torna um dificultador na construção de conceitos químicos. Assim, o desafio era planejar uma aula de química que ao mesmo tempo ajude no aprendizado desses alunos e seja interessante. Ao conversar com a professora de Ciências/Químicas foi relatado que a escola possui muito pouco material que aborde mais o ensino de Química/Ciências de maneira visual.

Continuamos a visita e enquanto caminhávamos pelos corredores da escola, os estudantes surdos nos recebiam com muita alegria e com olhares curiosos, logo perguntavam em libras o que estávamos fazendo ali. Nesse momento, nós professores e alunos tinham o desejo de nos comunicar, mas como? Somente, pelas expressões faciais de felicidade de estar conhecendo aquele espaço educacional, e percebendo o quanto temos a necessidade de saber libras.

A partir dai, vimos à importância do planejar atividades que sejam visuais que ajudam na construção e aprendizados dos conceitos químicos, visto que, a comunicação da maneira gestual-visual é a fonte de comunicação. Por isso, planejamos e desenvolvemos os 
experimentos leite psicodélico e pasta de dente de elefante mencionado na parte de metodologia, pois são experimentos coloridos e bonitos mais chamativos para a parte de visual, o que facilitaria o aprendizado para os estudantes. De acordo com Pereira, Benite e Benite (2011):

A aprendizagem de alunos surdos tem sido tradicionalmente encarada de acordo com as habilidades de comunicação expressiva e receptiva. Concebida como privação da audição, a surdez tem, nesse impedimento de acesso aos sons da fala, a principal dificuldade de aquisição da linguagem (PEREIRA; BENITE et al., 2011, p. 48).

Nesse sentido, ressaltamos a importância de planejar a aula com atividades e práticas de ensino que sejam mais voltadas para o visual. Desse modo, concordamos com Silva (2016) que: "Portanto, vemos que o/a Surdo/a tem sua maneira particular de interagir com o mundo e a experiência visual é umas das principais características que podem ser associadas à sua identidade humana e cidadã." (SILVA, 2016, p.32)

A seguir mostramos dois trechos de narrativas de licenciandas que visitaram a escola bilíngue:

\footnotetext{
"Estar na escola é um momento onde percebemos a realidade do outro, investigando como o ensino para surdos funciona e a maneira como que devemos seguir para proporcionar o ensino." (Licencianda A/ Estudante da disciplina de Educação Química V)

"No pouco período de tempo, que estive na escola, pude perceber que a relação estabelecida, por professor/aluno, que na minha opinião ali se estende mais que isso, é como se fossem, todos uma única família com amizade e solidariedade.”(Licencianda B/ Estudante da disciplina de Educação Química V)
}

Observamos que ambas licenciandas realizaram o exercício da alteridade percebendo a realidade do outro e colocando-se em seu lugar, no entanto pontos diferentes da visita às chamaram atenção como podem ser visto em seus relatos. Essa visita às ajudou a compreender mais o funcionamento da escola para desenvolver um melhor a planejamento de atividades a serem realizadas com estudantes surdos quando estes fossem visitar a universidade. As narrativas são construções de um narrador em diferentes momentos de sua experiência de vida, quando narramos historias estamos criando novamente o contexto do evento narrado, localizando-o novamente no tempo e espaço, inserindo personagens e falar (BASTOS, 2005; ALBUQUERQUE E GALIAZZI, 2011). Assim, percebemos que apesar de ambas licenciandas exercerem a alteridade através da experiência, para uma o que mais chamou atenção foi o modo como se dava o aprendizado nos alunos na escola e para a outra a relação entre professor e alunos. A visita à escola foi uma experiência de alteridade, de escuta 
sensível ao outro. Estávamos animados, com a esperança renovada em relação à educação do nosso país, e o desejo de fazer a diferença na formação de professores de Química.

\subsection{Visita dos estudantes surdos a Escola de Química e Alimentos na universidade}

Os três estudantes surdos juntamente com a professora de Ciências/Química e uma interprete chegaram por volta das $8 \mathrm{~h} 30$ na universidade e foram recebidos pelos licenciandos e os dois professores de Educação Química V. Conforme o planejamento, os licenciandos da disciplina se dividiram em dois grupos: o primeiro grupo mostraria o contexto da universidade, ou seja, os laboratórios de química, os alunos, os professores e mostraria como funcionam os cursos na área de química e o segundo grupo teria como função preparar os experimentos leite psicodélico e pasta de dente elefante descritos na parte metodologia desse artigo e fazer uma breve introdução sobre os conceitos químicos trabalhados nestes experimentos. Após estas atividades, um lanche coletivo foi realizado em forma de roda para que pudessem ser realizadas partilhas e troca de saberes entre todos os presentes.

As características visuais foram o que mais chamaram atenção dos estudantes surdos, por exemplo, a forma dos materiais utilizados no laboratório de química e a maneira como são organizados. Nos experimentos, que é a segunda parte da atividade, foram utilizados conceitos simples de químicas para facilitar a comunicação entre eles e também por tratar de alunos do ensino fundamental. Este foi um grande desafio para nós licenciandos pensar em uma forma mais simples e didática de explicar esses conceitos aos estudantes. $\mathrm{O}$ experimento do leite psicodélico foi realizado pelos próprios estudantes surdos, como é mostrado na figura 4, por tratar de um experimento com reagentes simples como leite, corante e detergente, nesse experimento explicou-se que o corante entre em contato com o detergente para the dar o aspecto de cor, que por sua vez o detergente entra em contato com o leite que proporciona o visual colorido no prato.

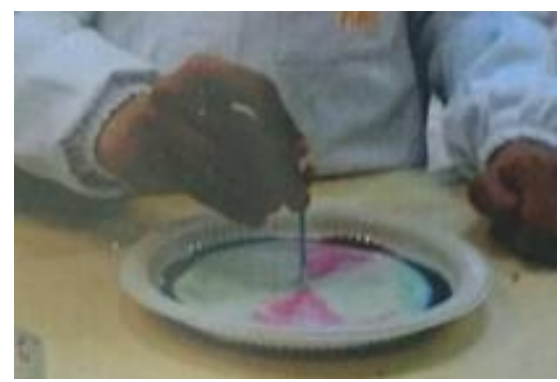

Figura 4 - Estudante da escola bilíngue realizando o experimento leite psicodélico Fonte: Os autores 
E no segundo experimento, que foi realizado de forma demonstrativa, devido o perigo do manuseio dos reagentes, explicou-se que a mistura de todos esses reagentes forma a espuma na qual ocorreu no experimento, conforme mostra figura 5, também foi comentado que essa mistura de reagentes se chama reação química.

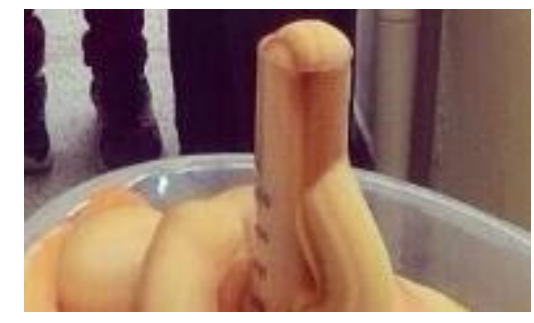

Figura 5 - Experimento pasta de dente de elefante que foi realizado na visita dos estudantes da escola bilíngue à universidade.

Fonte: Os autores

A experiência visual dos surdos envolve além de questões linguísticas, há todas as maneiras de significações comunitárias como: a utilização apelidos ou nomes visuais, metáforas visuais, imagens visuais, humor visual dentre outras várias significações. A surdez significa uma experiência visual pela presença da língua de sinais produzindo uma cultura que prescinde os sons (LEBEDEFF, 2010; SKLIAR, 2001).

Os alunos gostaram muito dos experimentos, o aspecto visual realmente foi o que mais chamaram atenção deles. A presença da professora de Ciências/Química e da interprete ajudou na explicação e construção de conceitos químicos, nos passando muita segurança na hora de realizar esta atividade, visto que, foi à primeira experiência de muitos licenciandos da disciplina envolvendo a inclusão. De acordo com Pereira, Benite e Benite (2011) concordamos que:

\footnotetext{
Os professores são os agentes principais na formação do sujeito crítico. A presença de um segundo agente na relação entre professores e alunos surdos deveria facilitar o processo de mediação do conhecimento científico devido à barreira linguística existente entre os primeiros. Entretanto, a utilização da linguagem química, social e culturalmente contextualizada deve respeitar sua constituição linguística funcional, pois só assim a linguagem funcionará como um recurso para significar a ação, isto é, deve ser apresentada por seu representante legítimo: o professor. Se este não utiliza a comunicação visual e se não há correspondentes para a simbologia química em libras, o aprendizado dessa Ciência estará comprometido (PEREIRA; BENITE et al., 2011, p. 51).
}

Ao final de todas as atividades licenciandos e professores formadores realizaram suas escritas narrativas sobre a atividade. A seguir mostramos dois trechos de narrativas de dois licenciandos a respeito da atividade desenvolvida com estudantes surdos: 


\begin{abstract}
"Foi muito gratificante, pois até então nunca tinha trabalhado com alunos surdos posso dizer que foi um desafio para todos nós por se tratar de alunos do ensino fundamental e de educação especial tratando-se de explicação de conteúdo, pois estes experimentos possuem explicação química mais “aprofundada".”(Licencianda C/ Estudante da disciplina de Educação Química V)

"O encantamento no olhar e sorrisos proporcionados tornou o ambiente aconchegante e feliz. Um momento ou outro pude conversar em libras com alguns educandos em um momento sendo proporcionado devido as disciplinas de Libras I e Libras II, me senti feliz.” (Licenciando D/ Estudante da disciplina de Educação Química V)
\end{abstract}

Ao analisar as duas narrativas percebemos a preocupação dos licenciandos com a questão da comunicação. Ambos, estavam preocupados em se comunicar com os estudantes surdos, o primeiro mais focado na construção dos conceitos científicos e o segundo mais com a própria comunicação mesmo com os estudantes a fim de fazer com que esses se sintam confortáveis e acolhidos no meio da universidade.

\title{
4. O que aprendemos ao viver a experiência com estudantes Surdos?
}

$\mathrm{Na}$ formação de professores é necessário o exercício da alteridade, abrir a possibilidade de colocar-se no lugar do outro. Na visita à escola, fomos convidados a viver a experiência da educação bilíngue para surdos, tivemos dificuldades na comunicação com estudantes surdos, que animados e curiosos, tentavam diálogo conosco professores e acadêmicos do curso de Química. Segundo, Santos (2016, p. 9) “a alteridade não existe em sua plenitude pela falta de conhecimentos específicos e de adequações para lidar com o diferente".

Os cursos de Licenciatura têm a inserção da Língua Brasileira de Sinais (Libras), como disciplinas obrigatórias, de acordo com o Decreto Federal 5.626/05, Libras I e Libras II, uma conquista significativa para comunidade surda e para formação de professores. Assim, reforçamos a importância das disciplinas de Libras I e II nos currículos das Licenciaturas, do qual favorece a convivência com professores surdos e o primeiro contato com a Língua Brasileira de Sinais. O exercício da alteridade inicia quando percebemos que a primeira língua do surdo não é o português. É importante reconhecer o direito da língua de sinais como primeira língua do estudante surdo, no entanto, sabemos das dificuldades de políticas públicas de inclusão escolar, de modo a favorecer a inclusão social. 
Conforme aponta, Santos (2016, p.8): “A inclusão deveria acontecer utilizando a língua de sinais, mas não ocorre porque alunos e professores ouvintes, não dominam Libras.” Portanto, se na escola prevalecer a cultura dos ouvintes, fica comprovado que a aprendizagem dos surdos é prejudicada e, de certa forma, a exclusão ainda existe. Entendemos que a comunidade escolar ao viver a inclusão das diferentes necessidades especiais, necessita exercer a alteridade enquanto conteúdo a ser trabalhado com os professores e estudantes ditos como “normais". "É necessário educar para o sensível, cultivando o respeito ao outro, o afeto em perceber as diferenças. Assim, outro argumento defendido é relacionado à formação inicial de professores, a importância de discutir a inclusão nos processos de ensino. Trata-se de um tema transversal que necessita ser abordado, e articulado à prática pedagógica do professor.

Carlos Skliar (1999) aponta para uma alteridade deficiente em relação às múltiplas formas de invenção e de exclusão que produz a normalidade no mundo atual. Aponta que a deficiência entendida, muitas vezes, como um fato biológico e com características universais, deveria ser problematizada epistemologicamente. Afirma que:

\begin{abstract}
É necessário inverter aquilo que foi construído como norma, como regime de verdade e como problema habitual: compreender o discurso da deficiência, para logo revelar que o objeto desse discurso não é a pessoa que está em uma cadeira de rodas ou o que usa um aparelho auditivo ou o que não aprende segundo o ritmo e a forma como a norma espera, senão os processos sociais, históricos, econômicos e culturais que regulam e controlam a forma acerca de como são pensados e inventados os corpos e as mentes dos outros. Para explicá-lo mais detalhadamente: a deficiência não é uma questão biológica e sim uma retórica social, histórica e cultural. A deficiência não é um problema dos deficientes ou de suas famílias ou dos especialistas. A deficiência está relacionada com a própria idéia da normalidade e com sua historicidade (SKLIAR, 1999, p.18).
\end{abstract}

O entendimento da alteridade na formação de professores torna-se fundamental, principalmente, quando se pensa no significado de nos processos de ensino e aprendizagem. É preciso educar para alteridade, mas para isso é preciso desenvolver a alteridade na formação de professores.

Desse modo, através das escritas narrativas dos licenciandos e dos professores formadores podemos compreender como foi dada a experiência de conhecer o contexto da inclusão pela conversa inicial com a professora da escola bilíngue, visita a escola e receber os estudantes surdos nos laboratórios de química da universidade. Também, por meio das escritas das narrativas, percebemos o fortalecimento do exercício da alteridade dos licenciandos na disciplina contribuindo para sua formação como futuros professores. Temos boas expectativas de realizar mais atividades como essa envolvendo o tema inclusão na formação de professores de Química. 


\section{Referências}

ALBUQUERQUE, F.; GALIAZZI, M.C. A formação do professor em rodas de formação. Revista Brasileira Estudos Pedagógicos. Brasília, v. 92, n. 231, p. 386-398, maio/ago. 2011.

BENITE, A. M. C.; NAVES, A. T.; PEREIRA, L. L.S. e LOBO, P. O. Parceria colaborativa na formação de professores de Ciências: a educação inclusiva em questão. In: ENCONTRO NACIONAL DE ENSINO DE QUÍMICA, 14, Curitiba. Anais... Curitiba: Imprensa Universitária da UFPR, 2008 (Trabalho em Anais de Congresso).

BRASIL.(1988). Constituição da República Federativa do Brasil. São Paulo: Encyclopaedia Britannica do Brasil.

BRUNER, J. A cultura da educação. Porto Alegre: ARTMED, 2001.

DORNELES, A. M. Rodas de investigação narrativa na formação de professores de química: pontos bordados na partilha de experiências. 2016. 113 folhas. Tese: (Doutorado em Educação em Ciências: Química da Vida e da Saúde) - Associação Ampla FURG/UFRGS/UFSM - Universidade Federal do Rio Grande - FURG, Rio Grande, 2016.

DORNELES, A. M.; GALIAZZI, M. C. Histórias de Sala de Aula de Professoras de Química: Partilha de Saberes e de Experiências nas Rodas de Formação do PIBID/FURG. Química Nova na Escola, vol. 34, n 4, p. 256-265, nov., 2012.

FOGAÇA, J. Canal do Educador. Disponível em: $<$ https://educador.brasilescola.uol.com.br/estrategias-ensino/experimento-leitepsicodelico.htm> Acesso em: 13 de Novembro de 2018

FOGAÇA, J. Canal do Educador. Disponível em: < https://educador.brasilescola.uol.com.br/estrategias-ensino/pasta-dente-elefante.htm > Acesso em: 13 de Novembro de 2018.

GONZAGA, J. C.; CORREA, J. J.; DE PAULA, F. A.. Cultura e Identidade Surdas: relação entre linguagem $e$ identidade (o contra ponto do outro). $5^{\circ}$ Congresso Internacional de Educação, Pesquisa e Gestão - CIEPG. Instituto Sul Americano de Pós-Graduação, Ensino e Tecnologia - ISAPG. Ponta Grossa - PR, 2013. p.1-9.

LEBEDEFF, T. Aprendendo a ler "com outros olhos": relatos de oficinas de letramento visual com professores surdos. Cadernos de Educação | FaE/PPGE/UFPel |, n. 36, p. 175 195, maio/agosto 2010.

LEITE, E. R. O. R.; LEITE, B. S. O Ensino de Química para Estudantes Surdos: A Formação dos Sinais. In: XVI Encontro Nacional de Ensino de Química (XVI ENEQ) e X Encontro de Educação Química da Bahia (X EDUQUI) Salvador, BA, Brasil - 17 a 20 de julho de 2012. Anais.. Salvador, 2012. (Trabalho em Anais de Congresso) Disponível em: < https://portalseer.ufba.br/index.php/anaiseneq2012/article/view/7562/5801> Acesso em: 23 de Dezembro de 2018. 
MELO, R. A.; SOBRINHO, L. D. G. EDUCAÇÃO MUSICAL E INCLUSÃO DE INDIVÍDUOS COM DEFICIENNCIA VISUAL: REALIDADES E PERSPECTIVAS. II CONEDU - Congresso Nacional de Educação. In: II CONEDU - Congresso Nacional de Educação Campina Grande, PB, Brasil - 14 a 17 de outubro de 2015. Anais... Campina Grande, 2015. (Trabalho em Anais de Congresso) Disponível em: <http://www.editorarealize.com.br/revistas/conedu/trabalhos/TRABALHO_EV045_MD1_SA 14_ID2993_19072015223707.pdf> Acesso em: 23 de Dezembro de 2018

Ministério da Educação e Cultura (1993). Plano Decenal de Educação para Todos - 1993 a 2003. Brasília: MEC.

Ministério da Educação e Cultura. (1999). Parâmetros Curriculares Nacionais-Adaptações Curriculares, Estratégias para a Educação de Alunos com necessidades Educacionais Especiais. Brasília: MEC/SEE.

QUADROS, R. M. Situando as diferenças implicadas na educação de surdos: inclusão/exclusão. Ponto de Vista, n.5, p. 81-111, 2003.

PEREIRA, L. L. S.; BENITE, C. R. M.; BENITE, A. M. C. Aula de Química e Surdez: sobre Interações Pedagógicas Mediadas pela Visão. Química Nova Na Escola, v. 33, n. 1, fevereiro/2011.

RODRIGUES, D.; LIMA-RODRIGUES, L. Formação de Professores e Inclusão: como se reformam os reformadores? Educar em Revista, n. 41, p. 41-60, jul./set. 2011.

SANTOS, M. I. A alteridade no contexto da inclusão de estudantes com deficiência auditiva (surdos) no ensino regular e na comunidade. Unoesc \& Ciência, v. 7, n. 1, p. 7-14, jan./jun. 2016.

Disponível

em: <https://editora.unoesc.edu.br/index.php/achs/article/viewFile/9875/pdf > . Acessado em: 05 de dezembro de 2018.

SILVA, J. S. ALMANAQUE NARRATIVO DO SER PROFESSOR DE QUÍMICA DE UM ESTUDANTE SURDO: desafios na formação inicial. 84 f. 2016.Trabalho de Conclusão de Curso (Química Licenciatura) - Escola de Química e Alimentos. Universidade Federal do Rio Grande, Rio Grande, 2016.

SILVEIRA, F. F.; NEVES, M. M. B. J. Inclusão Escolar de Crianças com Deficiência Múltipla: Concepções de Pais e Professores. Psicologia: Teoria e Pesquisa, vol. 22, n. 1, p. 79-88.

SOUSA, S. F.; SILVEIRA, H. E. Terminologias Químicas em Libras: A Utilização de Sinais na Aprendizagem de Alunos Surdos. Química Nova Na Escola, vol. 33, n 1, fevereiro/2011

SKLIAR, C. A invenção e a exclusão da alteridade "deficiente" a partir dos significados da normalidade. Educação e Realidade, v. 1, n. 24, 1999. Disponível em: <www.seer.ufrgs.br/educacaoerealidade/article/download/55373/33644 > Acessado em: 05 de dezembro de 2018. 
SKLIAR, C. Perspectivas políticas e pedagógicas da educação bilíngue para surdos. In: SILVA, S.; VIZIM, M. Educação Especial: múltiplas leituras e diferentes significados. Campinas: Mercado de Letras/ALB, 2001.

SUÁREZ, D. A documentação narrativa de experiências pedagógicas como estratégia de pesquisa-ação - formação de docentes. In: PASSEGGI, M.C.; BARBOSA, T. (Orgs.). Narrativas de formação e saberes biográficos. São Paulo: Paulus, 2008. 